\title{
Low dose ketamine pretreatment for alleviation of propofol injection pain- A study
}

\author{
Yamini Taloh $^{1}$, Nongthombam Ratan Singh ${ }^{2, *}$, Mumtak Borang ${ }^{3}$, Praneshwari Sinam ${ }^{4}$, J. F. Pyngrope ${ }^{5}$ \\ 1,3,4,5 Post Graduate trainee, ${ }^{2}$ Associate Professor, Dept. of Anaesthesiology, Regional Institute of Medical Sciences, Imphal, \\ Manipur, India
}

*Corresponding Author:

Email: drnratansingh@gmail.com

Received: $15^{\text {th }}$ December, 2017

Accepted: $08^{\text {th }}$ March, 2018

\begin{abstract}
Introduction: One of the most important disadvantages of propofol injection is intense burning pain. The present study was conducted with the aim to assess the effect of low dose Ketamine $(100 \mu \mathrm{g} / \mathrm{kg})$ in the alleviation of pain on propofol injection.

Materials and Methods: Patients who underwent surgical procedures under general anaesthesia were allocated into two groups viz. Group K ( $\mathrm{n}=35)$ - pre-treatment with ketamine $100 \mu \mathrm{g} / \mathrm{kg}(1 \mathrm{ml})$ and Group S $(\mathrm{n}=35)$ - pre-treatment with $0.9 \%$ normal saline $(1 \mathrm{ml})$ in this double-blinded, randomized study. After venous occlusion, ketamine was injected over 10 seconds, after which the occlusion was removed and over 20 seconds, the first $25 \%$ of the calculated dose of propofol was injected. The evaluation of the severity of pain was done by the verbal rating scale (VRS) during the injection of the induction agent for every 5 seconds and graded as 0 to 3 .The data were recorded and analysedusing unpaired ' $t$ ' test and chi-square test as and where appropriate.

Results: The demographic profiles were comparable between the two groups. It was observed that $42.9 \%$ of patients in normal saline and $80 \%$ in ketamine groups experienced no pain $(\mathrm{p}<0.05)$ while $31.4 \%$ and $17.1 \%$ of patients in normal saline and in ketamine groups respectively felt mild pain. No significant haemodynamic changes were observed in both the groups ( $p>0.05$ ).

Conclusion: It may be concluded that pre-treatment with low dose ketamine with a tourniquet just before propofol injection, significantly reduced the incidence and degree of propofol induced pain without significant adverse hemodynamic effects.
\end{abstract}

Keywords: Induction, Propofol, Pain, Low dose ketamine, Alleviation.

\section{Introduction}

Propofol, a popular intravenous induction agent, has high potential to induce intense burning pain on injection which varies between $28-90 \%$ in adults. ${ }^{1}$ Many factors seem to influence the propofol induced pain viz. Vein size and site, injection speed, comedication, $\mathrm{pH}$ of the agent, ${ }^{1}$ carrier intravenous fluid rate $^{2}$ temperature ${ }^{3}$ and concentration. ${ }^{4}$

Some of the pharmacological interventions include use of novel propofol emulsions, modified emulsions and micro-emulsions formulations, as well as diverse drugs and their combinations. ${ }^{5}$ The NMDA (n-methyl D aspartate receptor) antagonist, ketamine haspotent analgesic and local anaesthetic properties by inactivating these receptors either in the vascular endothelium or in the central nervous system. The local anaesthetic property of this drug attenuates the afferent pain pathway to reduce the propofol injection pain rather than central analgesic effect in the subanaesthetic doses.Few studies have evaluated the efficacy of ketamine in sub-anaesthetic doses for reducing the pain on propofol injection, but none has defined the optimal dose. ${ }^{6}$

We, therefore, performed a prospective, doubleblinded, randomised study to assess the efficacy of low dose ketamine in alleviation of propofol injection pain and to record the hemodynamic effects.

\section{Materials and Methods}

This double-blinded, randomized study was conducted in the Department of Anaesthesiology of a tertiary care teaching institute in northeast India during a period of two years after ethical committee approval. Seventy patients who underwent surgical procedures under general anaesthesia fulfilling the inclusion criteria viz. patients of both the genders in the age group of 18-60 years with American Society of Anaesthesiologists (ASA) physical status I or II were included in this study. Patients with neurological deficits, allergy to the study drug and propofol, uncontrolled diabetes and hypertension, cardiovascular and respiratory diseases, etc. were excluded from the study. The sample size was calculated based on a previous study ${ }^{1}$ by a web based calculation. Withan $\alpha$ value of 0.05 and beta value of 0.2 (power of study $=1$ $\beta=0.8$ i.e. $80 \%$ ), the size of the study was calculated at 32 patients in each group. Taking into consideration of a $5 \%$ dropout, the final sample size was taken as 35 patients in each group.

The patients were allocated into two groups viz. Group K $(\mathrm{n}=35)$ - pre-treatment with ketamine $100 \mu \mathrm{g} / \mathrm{kg}$. (1ml) and Group S $(\mathrm{n}=35)$ - pre-treatment with $0.9 \%$ normal saline $(1 \mathrm{ml})$ according to a computer generated randomization. The study drug was prepared by a colleague not involved in the study by diluting the drug with normal saline. A pneumatic tourniquet at 70 $\mathrm{mm} \mathrm{Hg}$ was applied to achieve venous occlusion of the forearm ${ }^{7}$ and ketamine was injected over 10 seconds. Then, the tourniquet was removed and the first $25 \%$ of the calculated dose $(2.5 \mathrm{mg} / \mathrm{kg})$ of propofol was 
injected over 20 seconds. The pain was assessed for every 5 seconds by an anaesthetist blinded to the studyusing the verbal rating scale (VRS) during injection of propofol, and graded it as 0 to 3 in accordance with scale advocated by McCrirrick and Hunter $^{8}$ and record the highest degree of pain. The study was taken as complete at this point and the remaining dose of propofol was given for the induction of anaesthesia. The standard protocol was followed for the anaesthetic procedure. The haemodynamic parameters were recorded in the peri-operative period at various time intervals viz. baseline, after test drug, after induction, after intubation, 3 minutes and 5 minutes after intubation. The findings were recorded and the windows based Statistical Package for Social Sciences Version 20.0 (SPSS Statistics for windows, Version 20 Armonk, NY: IBM Corp.) was used for dataanalysis byunpaired ' $\mathrm{t}$ ' test and chi-square test as and where appropriate.

\section{Results}

As shown in Table-1, it is observed that average age of patients in group $\mathrm{S}$ was 37.71 years while it was 36.94 years in the group $\mathrm{K}$. The average weight of saline group was $61.09 \mathrm{Kg}$ as against $57.03 \mathrm{Kg}$ for the ketamine group. The demographic profile in the two groups were comparable $(\mathrm{p}>0.05)$. There was no gender variation as well as ASA physical status between the groups $(p>0.05)$. The male-female ratios between the groups were almost the same and there was no difference in ASA physical status in both the groups $(\mathrm{p}>0.05)$ as shown in Table 1.

It is evident from table 2 and Fig. 1 that $42.9 \%$ of patients in Group S and $80 \%$ in Group $\mathrm{K}$ experienced no pain while mild pain was felt by $31.4 \%$ in Group $\mathrm{S}$ and $17.1 \%$ in Group K. In Group K, a relatively fewer patients $(2.9 \%)$ had moderate pain compared to $14.3 \%$ in Group S. Severe pain was observed in $11.4 \%$ of group $\mathrm{S}$ and no such incidence was seen in group $\mathrm{K}$, which was highly significant statistically $(\mathrm{p}=0.007)$. Also, the mean heart rate and mean arterial pressure (MAP) at different time intervals (fig. 2), showed no statistically significant difference between the groups $(\mathrm{p}>0.05)$.

Table1: Comparison of demographic profiles between the two groups

\begin{tabular}{|l|c|c|c|c|}
\hline \multirow{2}{*}{ Parameters } & \multicolumn{2}{|c|}{ Group } & \multirow{2}{*}{$\begin{array}{c}\text { Statistical } \\
\text { Value }\end{array}$} & $\begin{array}{c}\text { P- } \\
\text { value }\end{array}$ \\
\cline { 2 - 3 } & $\begin{array}{c}\text { Group K } \\
(\mathbf{n = 3 5})\end{array}$ & $\begin{array}{c}\text { Group S } \\
(\mathbf{n = 3 5})\end{array}$ & & \\
\cline { 2 - 3 } & Mean \pm SD & Mean + SD & & \\
\hline Age (yr) & $36.94 \pm 13.690$ & $37.71 \pm 13.796$ & & 0.831 \\
\hline Weight $(\mathrm{Kg})$ & $57.03 \pm 9.605$ & $61.09 \pm 15.691$ & & 0.280 \\
\hline Height $(\mathrm{Cm})$ & $163.06 \pm 10.123$ & $161.89 \pm 7.944$ & & 0.233 \\
\hline $\begin{array}{l}\text { Sex } \\
\text { (male:Female) }\end{array}$ & $\begin{array}{c}10: 25 \\
(28.6 \%: 71.4 \%)\end{array}$ & $\begin{array}{c}12: 23 \\
(34.3 \%: 65.7 \%)\end{array}$ & $\begin{array}{c}\chi^{2} \\
0.265\end{array}$ & 0.607 \\
\hline ASA class(I:II) & $\begin{array}{c}29: 6 \\
(82.9 \%: 17.1 \%)\end{array}$ & $\begin{array}{c}29: 6 \\
(82.9 \%: 17.1 \%)\end{array}$ & $\begin{array}{c}\chi^{2} \\
1.018\end{array}$ & \multirow{2}{*}{0.607} \\
\hline
\end{tabular}

Table 2: Degree of pain scores between the two groups

\begin{tabular}{|l|c|c|c|c|}
\hline \multirow{2}{*}{ Sensation of pain } & \multicolumn{2}{|c|}{ Group } & \multirow{2}{*}{$\boldsymbol{\chi}^{2}$-value } & P-value \\
\cline { 2 - 4 } & $\begin{array}{c}\text { Group K } \\
(\mathbf{n = 3 5})\end{array}$ & $\begin{array}{c}\text { Group S } \\
(\mathbf{n = 3 5})\end{array}$ & \multirow{2}{*}{12.067} & \multirow{2}{*}{0.007} \\
\hline 0: No pain & $28(80.0 \%)$ & $15(42.9 \%)$ & \\
\hline 1: Mild pain & $6(17.1 \%)$ & $11(31.4 \%)$ & & \\
\hline 2: Moderate pain & $1(2.9 \%)$ & $5(14.3 \%)$ & & \\
\hline 3: Severe pain & $0(0 \%)$ & $4(11.4 \%)$ & & \\
\hline
\end{tabular}




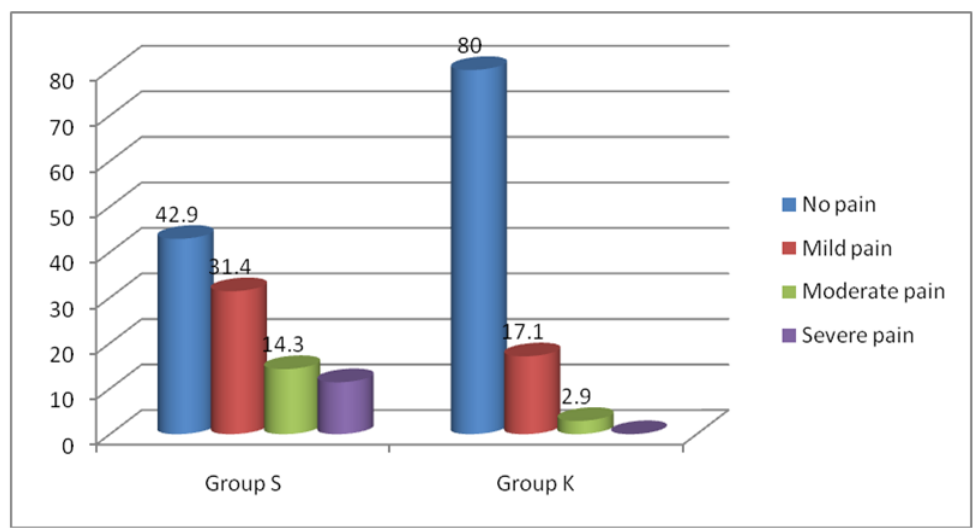

Fig. 1: Incidence (\%) of degree of pain between the two groups

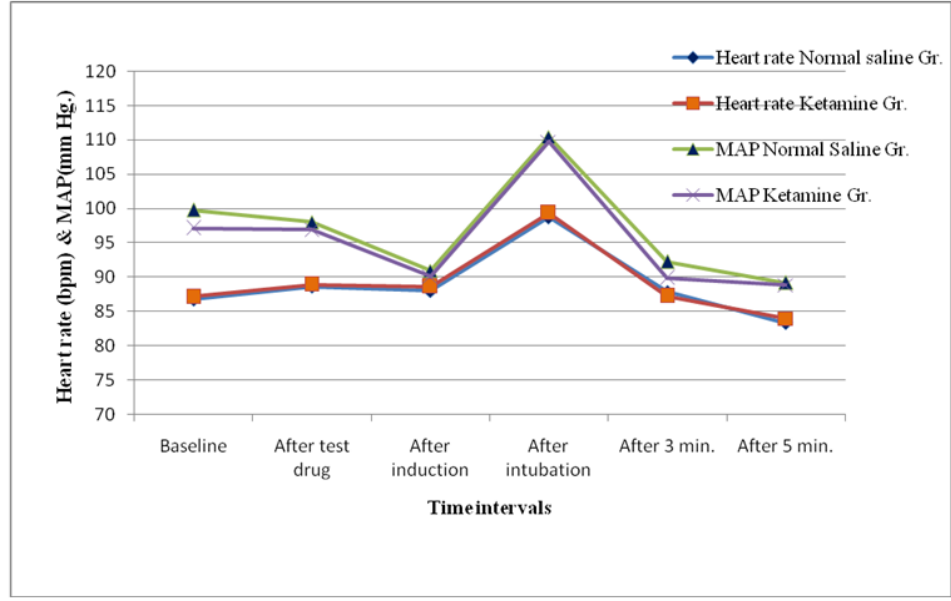

Fig. 2: Showing mean heart rate and mean arterial pressure at different time intervals in the two groups

\section{Discussion}

In anaesthetic practice, the quality of anaesthesia as judged by the patient is clearly influenced by any recall of discomfort or pain at the time of induction. Hynynen et $\mathrm{al}^{9}$ opined that the high incidence of severe pain with propofol made it a drug unlikely to gain popularity for routine clinical use. The incidence of pain with propofol injection ranged from $28 \%$ to $90 \%$ in adults, and $28 \%$ to $85 \%$ in children. ${ }^{10}$ Propofol, a phenol, may cause immediate or delayed pain on injection. The direct irritant effect could be the cause of the immediate pain while the delayed down occurring within half a minute could be due to kinin cascade. The increase in the local vein permeability and dilation may be due to the lipid solvent of propofol activating the plasma kallikrein-kinin system leading to release of bradykinin, which further intensifies the propofol injection pain. ${ }^{7,11-13}$ However, Ando et $\mathrm{al}^{14}$ were of the opinion that propofol causes vascular pain that occurs in response to prostanoids, particularly $\mathrm{PG} \mathrm{E}_{2}$.

Several workers have studied on the alleviation of propofol injection pain by using different methods. Sadawy et $\mathrm{al}^{15}$ studied on propofol induced pain using agents - ketamine, thiopental, meperidine, lidocaine and saline, and found ketamine to be the most effective agent in pain alleviation when combined with venous occlusion.

Ketamine may inactivate NMDA (n-methyl-Daspartatereceptor) receptors in the vascular endothelium or in the central nervous system. Further, it has local anaesthetic properties with potent analgesic action which attenuates the afferent pathway. ${ }^{16,17}$ Few studies have conducted the efficacy of ketamine in subanaesthetic doses for amelioration of propofol injection pain, but none has defined the optimal dose. ${ }^{1}$

In the present randomised, double blinded controlled study, the demographic profiles, weight, height and ASA physical status of the patients, were comparable between the study and the control groups $(\mathrm{p}>0.05)$.

In our study, $80 \%$ in the Group $\mathrm{K}$ experienced no pain compared to $42 \%$ in Group $\mathrm{S}$, whereas there was no incidence of severe pain the ketamine group $(\mathrm{p}=0.007)$. Similarly, Shriyan et $\mathrm{al}^{18}$ observed that there was no pain in $80 \%$ in their study which were similar to the findings of Qattan et $\mathrm{al}^{19}$, Chaudhuri et $\mathrm{al}^{20}$ and Koo et al. ${ }^{1}$ The peripheral local anaesthetic action of low dose ketamine might have attenuated the afferent pain pathway, rather than a central analgesic effect. ${ }^{17}$ Moreover, the chemical structure of ketamine is 
an analogue of the local anaesthetic, cocaine, thereby sharing some ofits effects. ${ }^{19}$

There was no incidence of severe pain in the Ketamine group in our study, which may favourably compared with the findings of Saadawy et al., ${ }^{15}$ Shriyan et al. ${ }^{18}$ and Zahedi et al. ${ }^{21}$. However, Quattan et al, ${ }^{19}$ observed severe pain $1(1.9 \%)$ in the ketamine group with the same dose, which is in contrast with findings of our study. Interestingly, the free fraction of propofol may be the cause for the slight delay before the pain is experienced; however, the exact mechanism of propofol injection pain is yet to be established. ${ }^{20}$

On pretreatment with ketamine, Qattan et al ${ }^{19}$ observed mild pain in $11.7 \%$, while Saadawy et al. ${ }^{15}$ observed moderate pain in $4 \%$. This is in agreement with the findings of our study. This may be due to the fact that ketamine has analgesic properties in subanaesthetic doses mediated via the $\mu$ or $\delta$ receptors, and it may also be a $\mu$ antagonist and $\kappa$ agonist. ${ }^{15}$

In the study by Tan $\mathrm{C} \mathrm{H}$ et al, ${ }^{16}$ hypotension was observed in $58 \%$ of the ketamine group and $60 \%$ in the control group, and no incidence of heart rate of less than 50 beat $/ \mathrm{min}$ was observed. In our study, with the dose of ketamine used, there was no hypotension with insignificant effect on mean arterial blood pressure and heart rate compared with control (saline) upto5mins after intubation which may be due to the fact that the cardio-stimulant effects of ketamine balanced the cardio-depressant effects of propofol. ${ }^{22}$

Venous stasis was achieved in our study with a pneumatic tourniquet $(70 \mathrm{mmHg})$, before the injection of the study drug, which could have helped in achieving the local action of the study drug at the peripheries. ${ }^{23}$

\section{Conclusion}

From the findings of our study, it may be concluded that pre-treatment with low dose ketamine with a tourniquet just before propofol injection, significantly reduced the incidence and degree of propofol induced pain without significant adverse hemodynamic effects.

Limitation of our study was that we did not investigate varied ketamine doses larger or lesser than $100 \mu \mathrm{g} / \mathrm{kg}$ or admixture with propofol; however we were concerned that larger doses would cause sedation and central action, and confound the results.

Further studies with varied doses of the study drug with varied intervals of pre treatment drug or admixtures of the drugs are suggested to come to a definite conclusion.

\section{Conflict of Interest: Nil Source of funding: Nil Acknowledgement: Nil}

\section{References}

1. Koo SW, Cho SJ, Kim YK, Ham KD, Hwang JH. Small dose Ketamine reduces the pain of propofol injection. AnesthAnalg. 2006 Dec;103(6):1444-7.

2. Huang CL, Wang YP, Cheng YJ, Susetio L, Liu CC. The effect of carrier intravenous fluid speed on the injection pain of propofol. Anaesth Analg 1995;81:1087-8.

3. Fletcher GC, Gillespie JA, Davidson JA. The effect of temperature upon pain during injection of propofol. Anaesthesia 1996;51:498-9.

4. Stokes DN, Roberson N, Hutton P. Effect of diluting propofol on the incidence of pain on injection and venous sequelae. Br J Anaesth 1989;62:202-3.

5. Jalota L, Kalira V, George E, Pace NL, Apfel CC, Radke $\mathrm{O}$, et al. Prevention of pain on injection of propofol; systemic review and meta-analysis. BMJ 2011;342:1-18.

6. Kad N, Malik P, Dureja J, Thakur A. Ketamine pretreatment to alleviate the pain of propofol injection: A randomized, double blinded study. The Internet $\mathbf{J}$ Anaesthesiol 2008;20(2). Available from: http://ispub.com/IJA/20/2/12725. Last accessed Jul 19 2015

7. Sapate M, Andurkar U, Markandeya M, Gore R, Thatte W. To study the effect of injection dexmedetomidine for prevention of pain due to propofol injection and to compare it with injection lignocaine. Brazilian J Anesthesiol.

Availablefrom:http://www.sciencedirect.com /science/article/pii /S 0104001413002091. Last accessed Jul 192015

8. McCirrick A, Hunter S. Pain on injection of propofol: the effect of injectate temperature. Anaesthesia 1990;45:443-4.

9. Hynynen M, Korttila K, Tammisto T. Pain on i.v injection of propofol in emulsion formulation short communication. Acta Anaesthesiol Scand 1985;29:651-2.

10. Singh DK, Jindal P, Singh G. comparative study of attenuation of pain caused by propofol intravenous injection, by granisetron, magnesium sulfate and nitroglycerine. Saudi J Anaesth 2011;5(1):50-4.

11. Shabana AM. Prevention of propofol injection pain, using lidocaine in a large volume does it make a difference? A prospective randomized placebo controlled double blinded study. Egyptian J Anaesthesia 2013;29:291-4.

12. Roehm KD, Piper SN, Maleck WH, Boldt J. Prevention of propofol Induced injection pain by remifentanil: a placebo controlled comparison with lidocaine. Anaesthesia 2003;58(2):165-70.

13. Scott RPF, Saunders DA, Norman J. Propofol: clinical strategies for preventing the pain of injection. Anaesthesia 1998;43:492-4.

14. Ando R, Watanbe C. Characterstics of propofol-evoked vascular pain in anaesthetized rats. Br J Anaesth 2005;95:384-92.

15. Saadawy I, Ertok E, Boker A. Painless injection of propofol: pretreatment with ketamine vs thiopental, meperidine, and lidocaine. Middle East J Anaesthesiol. 2007 Oct;19(3):631-44.

16. Tan CH, Onsiong MK, Kua SW. Tan CH, Onsiong MK, Kua SW. The effect of ketamine pretreatment on propofol injection pain in 100 women. Anaesthesia. 1998 Mar;53(3):302-5.

17. Stoelting RK. Non-Barbiturate induction drugs. In: Pharmacology and Physiology in Anesthetic Practice. 3rd ed. New York: Lippincott-Raven Publishers;1999:140-5.

18. Shriyan DR, Patil BM. Evaluation of low-dose ketamine for propofol injection pain: a randomized double blind, controlled trial. Inter J Anat Radio Sur; 2016 May:1-5. 
19. Qattan AR, Batra YK, Gajdosova B, Ward VD, Al-Harbi HSS, Odat MH. Effect of pretreatment with ketamine on propofol injection pain in children. Indian J of Anaesth. 2005;49(5):417-20.

20. Chaudhari A and Vaishnav D.Ketamine in prevention of pain during propofol injection Inter. J Bio Res. 2016;7(3):118-21.

21. Zahedi H, Nikooseresht M, Seifrabie M. Prevention of propofol injection pain with small dose ketamine. Middle East J Anaesthesiol. 2009;20(3):401-4.

22. Hui TW, Short TG, Hong W, Suen T, Gin T, Plummer J. Additive interaction between propofol and ketamine when used for anesthesia induction in female patients. Anaesthesiology 1995 Mar;82(3):641-8.

23. Mangar D, Holak EJ. Tourniquet at $50 \mathrm{mmHg}$ followed by intravenous lidocaine diminishes hand pain associated with propofol injection. AnaesthAnalg 1992;74:250-2. 